E. Favaro - A. Bottelli $\cdot$ B. Lozanoska-Ochser •

E. Ferioli · G. C. Huang - N. Klein - A. Chiaravalli •

P. Cavallo Perin - G. Camussi - M. Peakman •

P. G. Conaldi $\cdot$ M. M. Zanone

\title{
Primary and immortalised human pancreatic islet endothelial cells: phenotypic and immunological characterisation
}

Received: 2 May 2005 / Accepted: 21 July 2005 / Published online: 15 November 2005

(C) Springer-Verlag 2005

\begin{abstract}
Aims/hypothesis: Studies on the biology of the microvascular endothelial cells (MECs) that surround and penetrate the pancreatic islets are hampered by difficulties in isolating and culturing large numbers of pure cells. We aimed to morphologically and functionally characterise primary MECs purified and cultured from human islets, and to establish a simian virus 40 (SV40)-immortalised cell line from these primary cultures. Materials and methods: Human islet MECs were extracted and purified using anti-CD105 coated immunomagnetic beads, and endothelial markers and surface molecules analysed by flow cytometric analysis. An immortalised cell line was then established by using a chimeric adeno5/SV40 virus. Results: Islet MECs expressed classic and specific endothelial markers, a high basal level of intercellular adhesion molecule-1, and low levels of E-selectin and TNF (previously known as TNF- $\alpha$ ) inducible vascular cell
\end{abstract}

E. Favaro · P. C. Perin · G. Camussi · M. M. Zanone $(\bowtie)$ Department of Internal Medicine and Center of Experimental Medicine (CeRMS), University of Turin, Turin, Italy e-mail: mmz@libero.it

Tel.: +39-011-6336708

Fax: +39-011-6631184

A. Bottelli · E. Ferioli · A. Chiaravalli - P. G. Conaldi Departments of Medicine and Public Health and Pathology, University of Insubria,Varese, Italy

B. Lozanoska-Ochser · G. C. Huang · M. Peakman Departments of Immunobiology and Diabetes and Internal Medicine, Guy's, King's and St. Thomas's School of Medicine, London, UK

N. Klein

Department of Immunobiology, Institute of Child Health, London, UK

M. M. Zanone

Dipartimento di Medicina Interna,

Corso Dogliotti 14,

10126 Torino, Italy adhesion molecule-1. IFNG (previously known as IFN- $\gamma$ ) induced expression of HLA class II molecules. The immortalised islet MECs expanded rapidly, exhibited increased DNA synthesis, and were passaged approximately 30 times, without signs of senescence. They retained the endothelial characteristics of the parental cells, and behaved as the primary cells in terms of TNF stimulation of expression of adhesion molecules and support of leucocyte adhesion and transmigration. Conclusions/interpretation: The immortalised islet MECs that we have established could effectively represent a substitute for primary counterparts for in vitro studies on the role of the microvasculature in pathophysiological processes involved in type 1 and type 2 diabetes.

Keywords Adhesion molecules - Endothelial cells · Islets of Langerhans · Large T antigen - SV40

Abbreviations Api: $\alpha-1$ proteinase inhibitor $\cdot$ BrdU: 5bromo-2'-deoxyuridine - ICAM1: intercellular adhesion molecule-1 - MECs: microvascular endothelial cells $\cdot$ MFI: mean fluorescence intensity - PBMCs: peripheral blood mononuclear cells $\cdot$ RPE: R phycoerythrin $\cdot$ SV40: simian virus $40 \cdot \mathrm{T}-\mathrm{Ag}$ : T antigen - VCAM1: vascular cell adhesion molecule-1 vWF: von Willebrand's factor

\section{Introduction}

In addition to mediating transport of nutrients and metabolites, vascular endothelium plays a pivotal role in angiogenesis, haemostasis, and vascular permeability [1]. Through expression and secretion of an array of key immunological accessory molecules and mediators, the microvasculature also behaves as an active 'gatekeeper', in the control of leucocyte recruitment into the tissues and in the mediation of inflammation [2]. A deeper knowledge of tissue-derived endothelium might help us understand its physiological properties and the pathological processes occurring within a specific organ. It is, in fact, widely 
accepted that phenotype and function of microvascular endothelial cells (MECs) derived from different vascular beds are heterogeneous [3-8], supporting the proposal that tissue-specific vascular beds have specialised functions.

Against this background, pancreatic islet MECs exhibit distinctive structural features, reminiscent of the appearance of the renal glomerulus. The islet microcirculation is characterised by a dense network of sinusoidal capillaries with a distinctive fenestrated endothelium [9-13], branching from arterioles entering the islet. Each endocrine cell is in close proximity to an endothelial cell; this facilitates a rapid exchange of signals and substances. MECs are important in the delivery of oxygen and nutrients to endocrine cells, and also induce insulin gene expression during islet development [14], as well as providing secretory signals from other cells [15]. Importantly, the fenestrated islet microvascular endothelium not only facilitates rapid release of insulin into the circulation, but also appears to play a role in fine-tuning blood glucose sensing and regulation [12, 16-18]. Moreover, some studies support the possibility that the islet microvasculature participates in sensing the environment of the islets and generating signals to induce the growth and maintenance of the islets in response to physiological stimuli, such as insulin resistance [17-19]. Specific markers of the islet microvasculature are $\alpha-1$ proteinase inhibitor (Api) [11] and nephrin, a highly specific barrier protein [19], both of which are absent in other microvascular endothelial districts.

Intra-islet MECs are therefore likely to play a pivotal role in islet physiology and the pathogenesis of types 1 and 2 diabetes. Human and murine studies indicate that during autoimmune insulitis in type 1 diabetes the islet MECs adopt an activated phenotype and are probably involved in regulating mononuclear cell accumulation in the islets; these cells hyperexpress adhesion molecules, such as intercellular adhesion molecule 1 (ICAM1), PNAd and MAdCAM-1 (L-selectin ligands), as well as class II HLA molecules that are important in allowing mononuclear cells to transmigrate and home to pancreatic islets [20-24]. In nonobese diabetic mice, presentation of antigen by endothelial cells has been shown to be required for the homing of insulin-specific diabetogenic CD8 ${ }^{+} \mathrm{T}$ cells [25].

Most of our knowledge on the active participation of endothelial cells in physiopathological processes derives from studies on endothelial cells derived from umbilical vein, which are easily isolated and cultured [26]. However, it is conceivable that these large-vessel endothelial cells do not exhibit the phenotypic and functional characteristics of the relevant microvasculature [3-8, 27]. Studies on the biology of microvascular endothelial cells are hampered by difficulties in isolating and culturing large numbers of pure cells from any organ, and by their limited life span. Easier availability of endothelial cells would therefore facilitate definition of their role at specific sites, and enhance our understanding of the role of the microendothelium in pathophysiological processes, allowing questions to be addressed in vitro that are difficult or impossible to address in vivo.
The above observations prompted the present study, in which we describe the morphological and functional characterisation of primary MECs purified and cultured from human islets, and the establishment of a simian virus 40 (SV40)-immortalised cell line from these primary cultures.

\section{Subjects, materials and methods}

Islet endothelial cell isolation, purification and culture

Human islets were obtained from the pancreas of an organ donor using a modification of Ricordi's technique [28]. Islet isolations were carried out in the Cell Isolation Unit at King's College Hospital, London. These studies were carried out after obtaining informed consent and were approved by the local Ethical Review Committee.

Approximately 100,000 freshly obtained human islets that were 85 to $90 \%$ pure as assessed by dithizone staining were incubated at $37^{\circ} \mathrm{C}$ in RPMI (Invitrogen, Paisley, UK) supplemented with collagenase type I-A $(1 \mathrm{mg} / \mathrm{ml}$; Sigma Aldrich, Poole, Dorset, UK) and shaken every $15 \mathrm{~min}$ for $2 \mathrm{~h}$. To remove larger debris, the digest was passed through a $70-\mu \mathrm{m}$ filter, and the remaining cell suspension was resuspended and washed at $300 \times g$ for $10 \mathrm{~min}$ in RPMI $/ 2.5 \%$ FCS (Invitrogen). To obtain a single cell suspension, the resultant cell pellet was resuspended in $0.25 \%$ trypsin $/ 1 \mathrm{mmol} / 1$ EDTA (Invitrogen) for $10 \mathrm{~min}$ at $37^{\circ} \mathrm{C}$, washed and resuspended in $80 \mu \mathrm{l}$ of PBS $/ 0.5 \%$ FCS, supplemented with $20 \mu \mathrm{l}$ of anti-CD105 immunomagnetic beads (Dynal, Wirral, Merseyside, UK). After $15 \mathrm{~min}$ at $6^{\circ} \mathrm{C}$ with an end-over-end rotation, cells were washed, resuspended in appropriate buffer and positively selected using an MP3 magnetic cell particle separator (Dynal) according to the manufacturer's instructions. Finally, the enriched islet endothelial cells were resuspended in MEC growth medium with $20 \% \mathrm{FCS}$, $10 \mathrm{mmol} / \mathrm{l} \mathrm{L}$-glutamine, $12 \mu \mathrm{g} / \mathrm{ml}$ endothelial cell growth factor, $10 \mathrm{ng} / \mathrm{ml}$ epidermal growth factor, $1 \mu \mathrm{g} / \mathrm{ml}$ hydrocortisone (all from TCS CellWorks, Buckinghamshire, UK) and antibiotics (100 IU/ml penicillin, $100 \mu \mathrm{g} / \mathrm{ml}$ streptomycin), and transferred onto tissue culture plates coated with endothelial cell attachment factor (Sigma). Cells were grown to confluence, subcultured and analysed for the expression of endothelial cell markers [19].

Establishment of the immortalised islet endothelial cell line

The immortalisation of the islet endothelial cells was effected using a chimeric adeno5/SV40 virus [29]. The recombinant virus was achieved by cloning SV40 large T antigen (T-Ag) DNA in adenovirus type 5 vector. A $25-\mathrm{cm}^{2}$ flask of islet MECs at the third passage after isolation and purification was infected with the purified chimeric virus for $2 \mathrm{~h}$ at $37^{\circ} \mathrm{C}$ in serum-free medium at a multiplicity of infection of 200. The infected islet MECs were washed, 
incubated overnight in complete medium, and finally subcultured. At 28 days post-infection SV40-induced foci were identified, individually detached and propagated. The cells derived from these foci were characterised in order to control the expression of endothelial markers. The SV40induced cell line was established by subculturing the cells every 5 days at a split ratio of $1: 2$.

The transformation of the immortalised cells was evaluated by assessing their ability to form colonies in soft agar. Moreover, to assess their tumorigenic potential in vivo, $1 \times 10^{6}$ cells were resuspended in $200 \mu \mathrm{l}$ of medium, chilled on ice, added to $200 \mu \mathrm{l}$ of Matrigel (Sigma) at $4^{\circ} \mathrm{C}$ and injected subcutaneously into the left back of SCID mice (Charles River, Jackson Laboratories, Bar Harbor, ME, USA) via a 26-gauge needle using a 1-ml syringe.

The possibility that these cells might produce adenovirus-SV40 recombinant virions was also considered by detecting SV40 large T-Ag sequences (see below) in DNA samples extracted from culture supernatants that had been precipitated with polyethylene glycol $8,000(10 \%)$ in $\mathrm{NaCl}$ $0.4 \mathrm{~mol} / \mathrm{l}$, in order to concentrate any recombinant virions released by the immortalised cells.

Detection of SV40 large T-Ag in immortalised islet MECs

The expression of SV40 large T-Ag in the nuclei of the immortalised islet MECs was revealed by immunocytochemical staining. The cells were cultured in chamber slides for $24 \mathrm{~h}$ at $37^{\circ} \mathrm{C}$ and then fixed in $10 \%$ paraformaldehyde for $15 \mathrm{~min}$ at room temperature. The cell monolayers were incubated with $3 \%$ hydrogen peroxide for $10 \mathrm{~min}$ at room temperature, treated twice in a microwave oven at $700 \mathrm{~W}$ for $5 \mathrm{~min}$, and washed in TBS $\mathrm{pH} 7.4$ and $2 \%$ Triton X-100; then, the cells were incubated overnight at $4^{\circ} \mathrm{C}$ with $4 \mu \mathrm{g} / \mathrm{ml}$ of monoclonal antibody specific to SV40 large T-Ag (Santa Cruz Biotechnology, Santa Cruz, CA, USA). After washing with TBS-Triton the cultures were treated for $1 \mathrm{~h}$ at room temperature firstly with biotinylated anti-mouse Igs and then with streptavidin conjugated to horseradish peroxidase. Finally, the cells were stained with $0.03 \%$ benzidine and counterstained with haematoxylin and eosin.

To reveal the presence of the complete transcript of SV40 large T-Ag, $1 \mu \mathrm{g}$ of total RNA was reverse transcribed using a first strand synthesis kit (Boehringer Mannheim, Indianapolis, IN, USA). The PCR mixture contained $1 \mu \mathrm{g}$ of cDNA, buffer with nucleotides $(200 \mu \mathrm{mol} / \mathrm{l}$ each $)$, $1.5 \mathrm{mmol} / 1 \mathrm{MgCl}_{2}, 1 \mathrm{U}$ of Taq polymerase (Invitrogen), and $0.2 \mu \mathrm{mol} / 1$ of specific primers (forward primer: 5'- ATGGA TAAAGTTTTAAAC-3'; reverse primer: 5'-TGAGGTT CAGGGGGAGGT- $\left.3^{\prime}\right)$. The reaction was carried out for 40 cycles $\left(30 \mathrm{~s}\right.$ at $94^{\circ} \mathrm{C}, 40 \mathrm{~s}$ at $53^{\circ} \mathrm{C}$ and $30 \mathrm{~s}$ at $72^{\circ} \mathrm{C}$ ), and the amplicon of 2,124 bp was analysed in a $1.5 \%$ agarose gel. cDNA from primary cells and the vector with cloned large $\mathrm{T}-\mathrm{Ag}$ served as controls.
SV40 large T-Ag DNA sequences were also detected by semi-nested PCR, as described [30]. In the first round of PCR, $1 \mu \mathrm{g}$ of DNA was amplified using $0.2 \mu \mathrm{mol} / 1$ of specific primers (Invitrogen, Carlsbad, CA, USA) (forward primer: 5'-CTTTGGAGGCTTCTGGGATGCAACT-3'; reverse primer: 5'-GCATGACTCAAAAAACTTAGCAATTCTG$\left.3^{\prime}\right)$. Using the same forward primer and a different reverse primer (5'-GAAAGTCTT TAGGGTCTTCTACC-3'; Invitrogen), $10 \mu \mathrm{l}$ of first-round PCR products were re-amplified. The amplicons (first-round: $575 \mathrm{bp}$; second-round: $543 \mathrm{bp}$ ) were analysed in a $2 \%$ agarose gel. DNA from primary cells and SV40-immortalised human podocytes served as controls.

Phenotypic characterisation, detection of surface molecules, and immunofluorescence studies

The endothelial phenotype of primary and immortalised islet MECs was assessed by flow cytometric analysis, staining for basal expression of endothelial markers and adhesion molecules, with cell aliquots permeabilised for intracellular staining, as described [19].

Cells were stained at room temperature with saturating amounts of anti-human monoclonal antibody against CD105 conjugated to R phycoerythrin (RPE) (undiluted; Serotec, Oxford, UK), CD31-RPE (undiluted; Serotec), VE-cadherin (dilution 1:30; BD PharMingen, San Diego, CA, USA), CD146-RPE (clone P1H12, dilution 1:100; Chemicon, Temecula, CA, USA), E-selectin-FITC (CD62E, dilution 1:20), ICAM1 (CD54, 1:10), vascular cell adhesion molecule-1 (VCAM1) (CD106, 1:20) (all from Serotec), CD40-FI TC (undiluted; Euroclone, Devon, UK), CD154-FITC (undiluted; Euroclone), and rabbit anti-human von Willebrand's factor (vWF) antiserum (dilution 1:200; Sigma).

After washing, RPE-conjugated $\mathrm{F}\left(\mathrm{ab} \mathrm{b}^{\prime}\right)_{2}$ fragment of goat anti-mouse immunoglobulins or FITC-conjugated antirabbit immunoglobulins (Dako, Glostrup, DK) were used as secondary antibodies. Cells were analysed by flow cytometry using CellQuest software (BD Biosciences, Erembodegem, Belgium), and results expressed as mean fluorescence intensity (MFI) and/or percentage of positive gated events, with gates established using appropriate isotype control antibodies (Serotec or PharMingen). For the adhesion molecules, expression is presented as the mean of five separate flow cytometric analyses. Expression of E-selectin, ICAM1, VCAM1, CD40 and CD154 was also re-analysed after incubation with recombinant human TNF (previously known as TNF- $\alpha$ ) $10 \mathrm{ng} / \mathrm{ml}$ (Sigma) for 4 to $12 \mathrm{~h}$.

For HLA class II molecule staining, cells were incubated for $30 \mathrm{~min}$ at $4^{\circ} \mathrm{C}$ with mouse anti-human antibodies against HLA-DR (BD PharMingen) and analysed at baseline and at 24, 48 and $72 \mathrm{~h}$ after stimulation with $100 \mathrm{IU} / \mathrm{ml}$ IFNG (previously known as IFN- $\gamma$ ).

Immunofluorescence staining for nephrin on cultured islet MECs was performed as previously described [19]. 
For intracellular staining of Api, cells, permeabilised with $0.5 \%$ Triton X-100, were stained with goat anti-human Api polyclonal antibody (1:50) (Rockland, Gilberstville, PA, USA) as described [11].

\section{Proliferation assay}

Cells were seeded into 96-well plates and cultured for $48 \mathrm{~h}$. DNA synthesis was then measured by a cell proliferation 5-bromo-2'-deoxyuridine (BrdU)ELISA (Roche Diagnostics, Mannheim, Germany), following the manufacturer's instructions. This is a colorimetric immunoassay, based on the measurement of BrdU incorporation during DNA synthesis. Eight separate experiments were performed, each in triplicate. Data were expressed as percentage change amongst immortalised vs primary MECs (mean $\mathrm{Abs}_{450 \mathrm{~nm}}$ immortalised $\mathrm{MECs} / \mathrm{mean} \mathrm{Abs}_{450 \mathrm{~nm}}$ primary MECs x 100).

\section{In vitro angiogenesis assay}

To determine whether islet MECs were able to align to form cord-like structures, also defined as capillary-like, they were cultured on polymerised Matrigel, a basementmembrane-like matrix. Matrigel was applied to glass slides and allowed to gel at $37^{\circ} \mathrm{C}$. Primary and immortalised islet MECs were seeded on to the Matrigel, cultured and observed by microscopy for 1 to $24 \mathrm{~h}$ to check for formation of cord-like structures. Cord formation was imaged by phase-contrast microscopy, and representative fields were photographed (Windows MicroImage, 3.4; CASTI Imaging, Venice, Italy) using a low-light video camera.

\section{Scanning electron microscopy}

Cells (approximately $10^{4}$ cells in $200 \mu$ of medium) were seeded on gelatin-coated eight-well chamber slides (Nalgene Nunc International, Rochester, NY, USA) and cultured for 24 to $48 \mathrm{~h}$ to subconfluence. Cells untreated or treated with TNF $(10 \mathrm{ng} / \mathrm{ml})$ for $1 \mathrm{~h}$ were fixed in Karnowsky's fixative for $1 \mathrm{~h}$, dehydrated in alcohol, dried and coated with gold by sputter coating (Emitech, Ashford, UK). They were then examined in a scanning electron microscope (JSM T300; Jeol, Tokyo, Japan) operating at $25 \mathrm{kV}$.

Mononuclear cell adhesion and transwell migration assays

Peripheral blood mononuclear cells (PBMCs) were obtained by Ficoll-Hypaque centrifugation of heparinised blood from a healthy donor, washed in Hanks' balanced salt solution and the pellet resuspended in endothelial cell medium at a concentration of $1 \times 10^{6}$ cells $/ \mathrm{ml}$. To measure PBMC adhesion to islet MEC monolayers, $1 \times 10^{6}$ PBMCs in $1 \mathrm{ml}$ of medium were added to each well of confluent cells and incubated for $1 \mathrm{~h}$ at $37^{\circ} \mathrm{C}$. Non-adherent cells were removed by aspiration of the supernatant and two washes. Endothelial cells and adherent PBMCs were dispersed by incubation with non-enzymatic cell dissociation solution
Fig. 1 Representative morphological analysis of primary and immortalised islet MECs. Light microscopy of cultured primary (a) and immortalised (b) islet MECs observed by phase contrast (original magnification $\times 200$ ). The cells exhibited an elongated shape. Immortalised cells sometimes had a more granular appearance, and retained a similar morphology. Bars: $10 \mu \mathrm{m}$. c, d Representative micrographs created by scanning electron microscopy of untreated primary islet MECs (c) or of MECs treated with TNF $(10 \mathrm{ng} / \mathrm{ml})$ for $1 \mathrm{~h}(\mathbf{d})$. TNF treatment induced marked retraction of the cells, ruffling of the surface, and loss of reciprocal contacts; nuclei and nucleoli were no longer visible. Arrows indicate cellular fenestrations (original magnification $\times 1,500$ ). Bars: $1 \mu \mathrm{m}$. Inset (c): representative magnification of a cellular fenestra (original magnification $\times 15,000)$. Bar: $0.1 \mu \mathrm{m}$ a

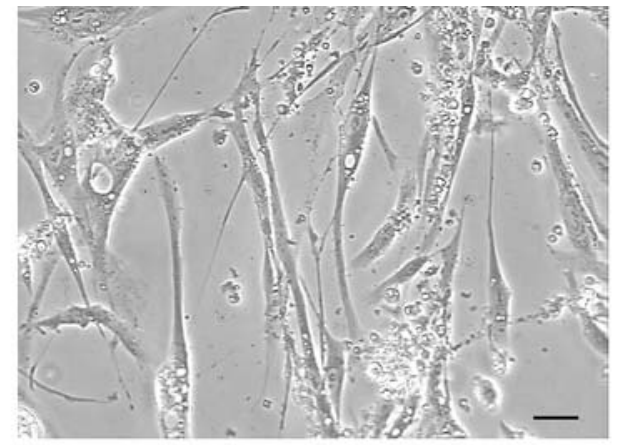

C

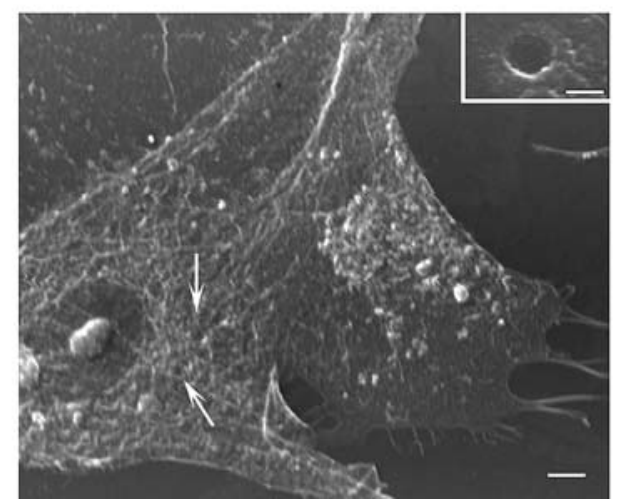

b

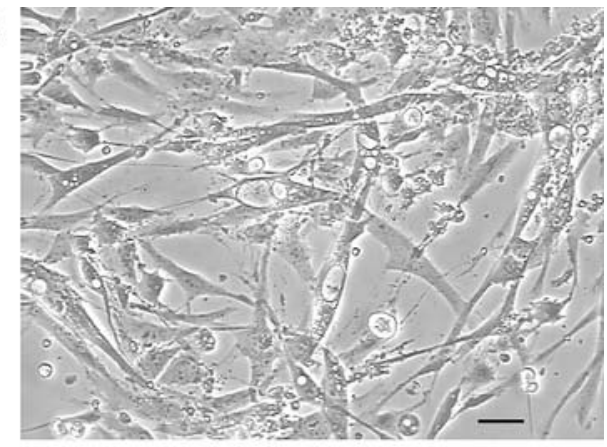

d

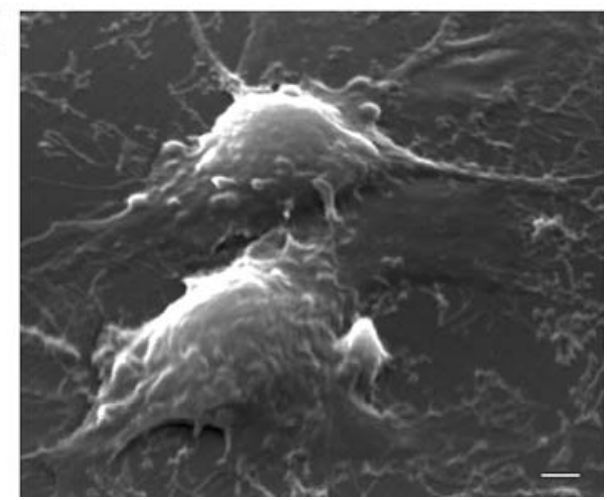


and then washed. The cell pellet was resuspended and aliquoted for staining for all PBMCs and monocytes (with $10 \mu \mathrm{l}$ of a mix of anti-human CD45-FITC and anti-CD14RPE monoclonal antibodies; Dako) and isotype control for $30 \mathrm{~min}$ at $4^{\circ} \mathrm{C}$. It was then washed and analysed by immunofluorescent staining and flow cytometry.

In parallel experiments, PBMCs were labelled for $5 \mathrm{~min}$ with $4 \mu \mathrm{mol} / 1 \mathrm{PKH} 2$ (Sigma), a green fluorescent membrane stain, following the manufacturer's instructions, and subsequently $1 \times 10^{6}$ PBMCs were added to cell monolayers as above. Adherent cells were counted by digital analysis (Windows MicroImage) of images, using a video camera, and expressed as the mean of cells counted in ten $\times 200$ inverted microscope fields.

To evaluate whether PBMC adhesion could be upregulated by TNF, primary and immortalised cell monolayers were treated with TNF $(10 \mathrm{ng} / \mathrm{ml})$ for $12 \mathrm{~h}$, and adhesion experiments performed as above. All the adhesion studies were carried out using duplicate wells, and three different sets of experiments were performed.

In migration experiments, $3-\mu \mathrm{m}$ pore size polyethylene transwells (Corning Costar, MA, USA) were prepared by coating transwell inserts with endothelial cell attachment factor. Endothelia were seeded at $2 \times 10^{5}$ cells per transwell insert and allowed to grow to confluence. Endothelial integrity was assessed by a trypan blue-albumin permeability assay, sampling aliquots of the bottom well and measuring absorbance at $590 \mathrm{~nm}$, as described [31]. PBMCs, at a concentration of $5 \times 10^{5}$ per well, were added to the upper chamber of the transwell. PBMCs migrating into the lower chamber were quantitated by direct sampling and counting in a haemocytometer at 1,4 and $18 \mathrm{~h}$. In parallel experiments, transwells were incubated in the presence of TNF $(10 \mathrm{ng} / \mathrm{ml})$ for 4 and $12 \mathrm{~h}$.

All the transwell studies were carried out using duplicate wells and counting of the cells in the lower chamber was in triplicate. Results were expressed as a percentage of the starting cell numbers.

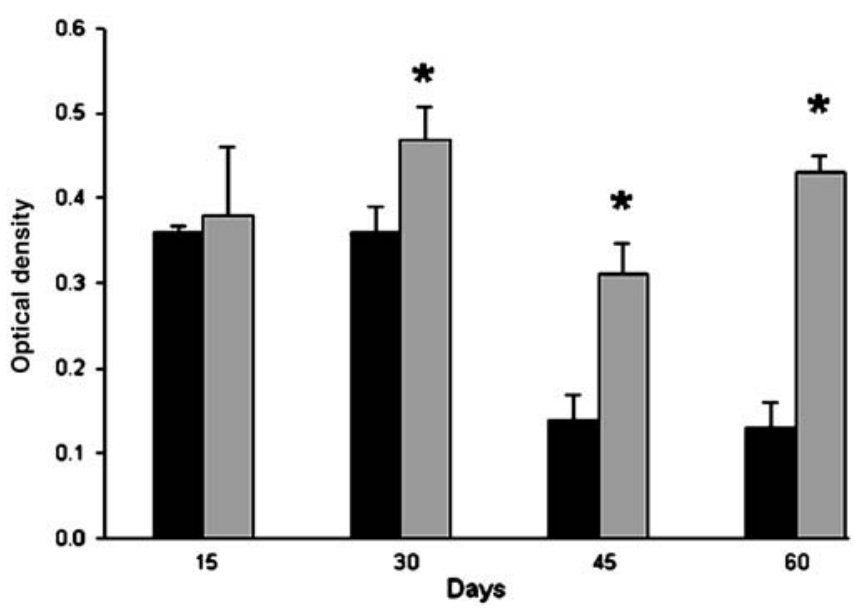

Fig. 2 Time course proliferation data. BrdU incorporation by primary (black) and immortalised (grey) islet MECs during 60 days of culture. Data are expressed as mean value \pm SD of three experiments. ${ }^{*} p<0.05$ vs primary islet MECs
Statistical analysis

BrdU incorporation, mean values of MFI, the mean percentage of positive cells for surface molecules, and the numbers of adherent PBMCs between primary and immortalised cells were compared using the MannWhitney $U$-test. Data were analysed using the SPSS statistical package (SPSS, Chicago, IL, USA), and $p$ values less than 0.05 were considered significant.

\section{Results}

Primary and immortalised islet endothelial cell culture and phenotype

Isolated primary islet MECs were elongated in shape, and grew in monolayer (Fig. 1a), without the typical cobblestone-like endothelial cell morphology. The morphology of the immortalised counterparts of islet MECs was essentially indistinguishable from that of the primary cells, although they tended to assume a more granular appearance (Fig. 1b). The viability of both cell types was 90 to $96 \%$ as detected by trypan blue exclusion.

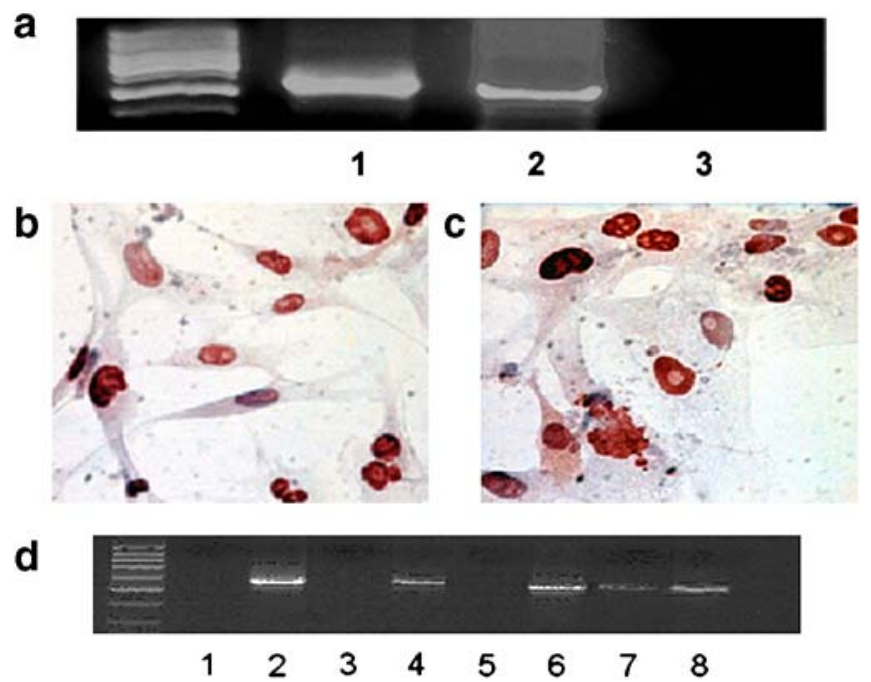

Fig. 3 Representative immunocytochemical staining and PCR analysis of large $\mathrm{T}-\mathrm{Ag}$ expression in immortalised islet MECs. a Representative agarose gel resolving RT-PCR products after amplification for full-length SV40 large T-Ag, detected as a band of 2124 bp. Lane 1, immortalised islet MECs; lane 2, vector with cloned large T-Ag; lane 3, primary islet MECs. b, $\mathbf{c}$ Micrographs of immortalised islet MECs showing that the nuclear staining (red) for SV40 large T-Ag increased in intensity among early (10 passages) (b) and late (30 passages) (c) subcultures. Original magnification: $\times 200$. This was confirmed (d) by semi-nested PCR for large T-Ag, detecting the first-round product $(575 \mathrm{bp}$ ) (lane 1, primary MECs; lane 2, immortalised podocytes; lane 3 early subcultures of immortalised MECs; lane 4, late subcultures) and the secondround product ( $543 \mathrm{bp}$ ) (lane 5 primary MECs; lane 6, immortalised podocytes; lane 7 early subcultures of immortalised MECs; lane 8, late subcultures). The first-round product was negative in early subcultures of immortalised cells, and the intensity of the secondround product increased in late subcultures. Three different experiments were performed with similar results 
Fig. 4 Representative flow cytometric analysis and immunofluorescence micrographs of immortalised islet MECs. Detection of staining for CD31 (a), endoglin (CD105) (b), transmembrane glycoprotein melanoma cell adhesion molecule (CD146) (c), vWF (d), and VE-cadherin (e). Thin lines represent the corresponding isotype control antibodies. Repeated experiments, every three to four subcultures, were performed with similar results. Primary islet MECs exhibited similar patterns. f, g Immunofluorescence enabled nephrin $(\times 400)$ and Api $(\times 200)$, respectively to be detected in immortalised cells. The appropriate controls with irrelevant immunoglobulins were negative (data not shown). h Immortalised islet MECs cultured on Matrigel for $24 \mathrm{~h}$ aligned to form capillarylike structures (representative phase contrast micrograph $\times 100$ ). Bars: $10 \mu \mathrm{m}$ a

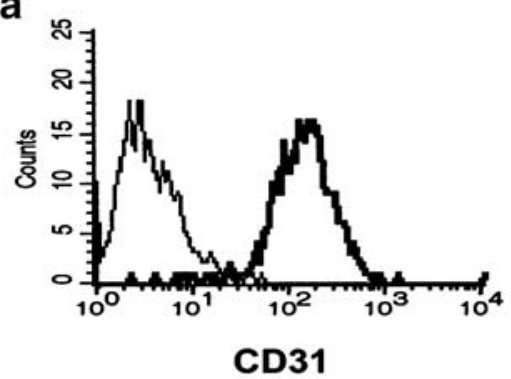

C

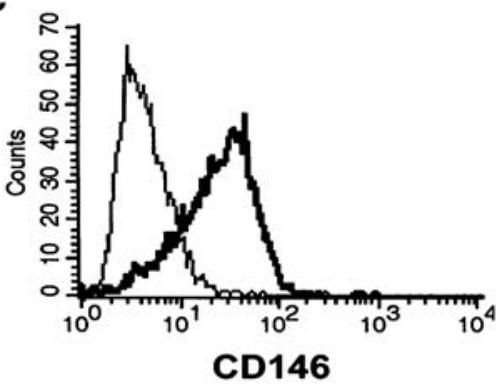

e

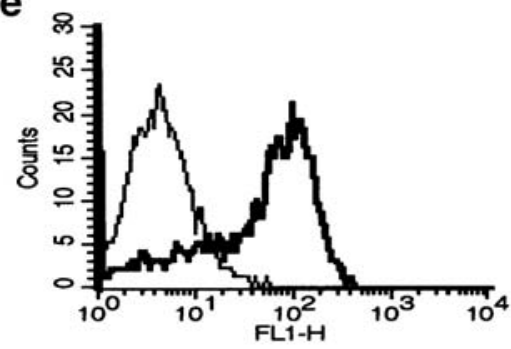

g

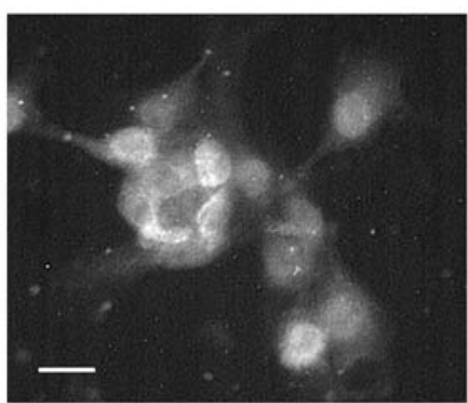

b

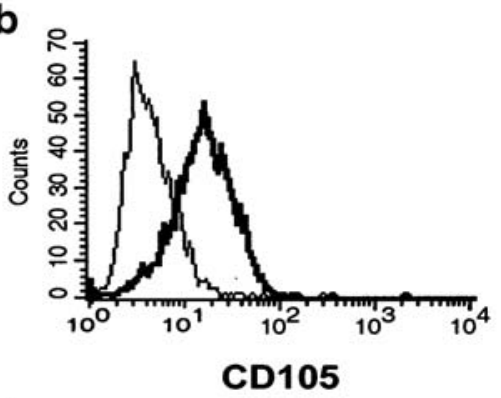

d

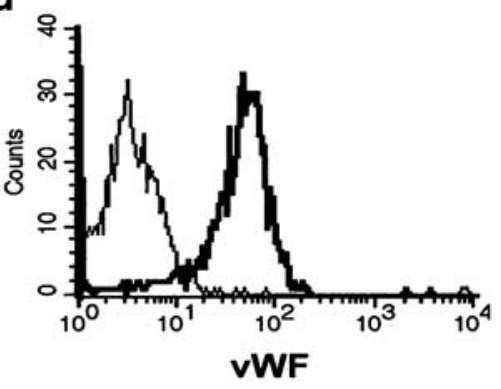

f

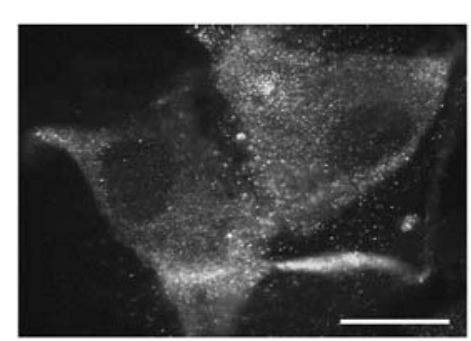

h

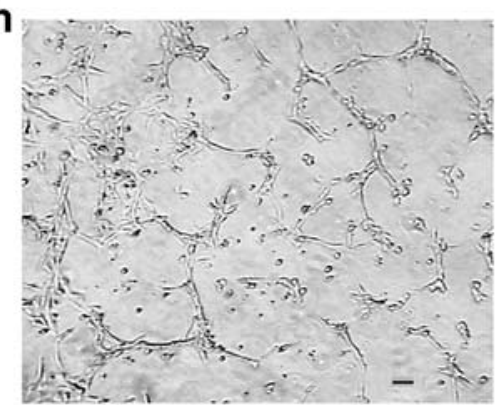

By scanning electron microscopy, primary cells appeared flat with a rather smooth surface, and with nuclei and nucleoli visible throughout the even cytoplasm surface.
Several fenestrations were detectable (Fig. 1c). TNF treatment stimulated cell retraction, ruffling of the surface, and loss of reciprocal contacts (Fig. 1d). Nuclei and

Table 1 Mean fluorescence intensity and percentage of cells positive for expression of endothelial cell markers repeatedly assessed during 3 months of culture of immortalised islet MECs

\begin{tabular}{|c|c|c|c|c|c|c|c|c|}
\hline & \multicolumn{2}{|c|}{15 days } & \multicolumn{2}{|c|}{1 month } & \multicolumn{2}{|c|}{2 months } & \multicolumn{2}{|c|}{3 months } \\
\hline & MFI & Percentage & MFI & Percentage & MFI & Percentage & MFI & Percentage \\
\hline CD31 & 114.9 & 99.8 & 103 & 84 & 55 & 80 & 71 & 86 \\
\hline CD105 & 18.7 & 77.3 & 36 & 89 & 23.2 & 89 & 25.2 & 65 \\
\hline CD146 & 81.9 & 97.1 & 85.6 & 93 & 52 & 94.9 & 81 & 82 \\
\hline vWF & 30 & 91.7 & 49 & 94 & 31 & 91.8 & 22 & 90 \\
\hline VE-cadherin & 30 & 79.6 & 22 & 59 & 50 & 89 & 49 & 66 \\
\hline
\end{tabular}

$M F I$ mean fluorescence intensity, $v W F$ von Willebrand's factor 
Fig. 5 Representative flow cytometric analysis of adhesion molecules and HLA-DR on immortalised islet MECs. Detection of staining for ICAM1 (a), VCAM1 (b), and E-selectin (c) expression after treatment (dashed line), or not (dark line) with TNF (10 ng/ml for $4 \mathrm{~h}$ ). d IFNG $(100 \mathrm{IU} / \mathrm{ml})$ induced expression of HLA-DR molecules (dashed line) in CD105positive islet MECs, which are represented (e) as signals in the upper right-hand quadrant. Thin lines (a-d) represent the corresponding isotype control antibodies. Four to six experiments were performed with similar results. Primary islet MECs exhibited similar patterns a
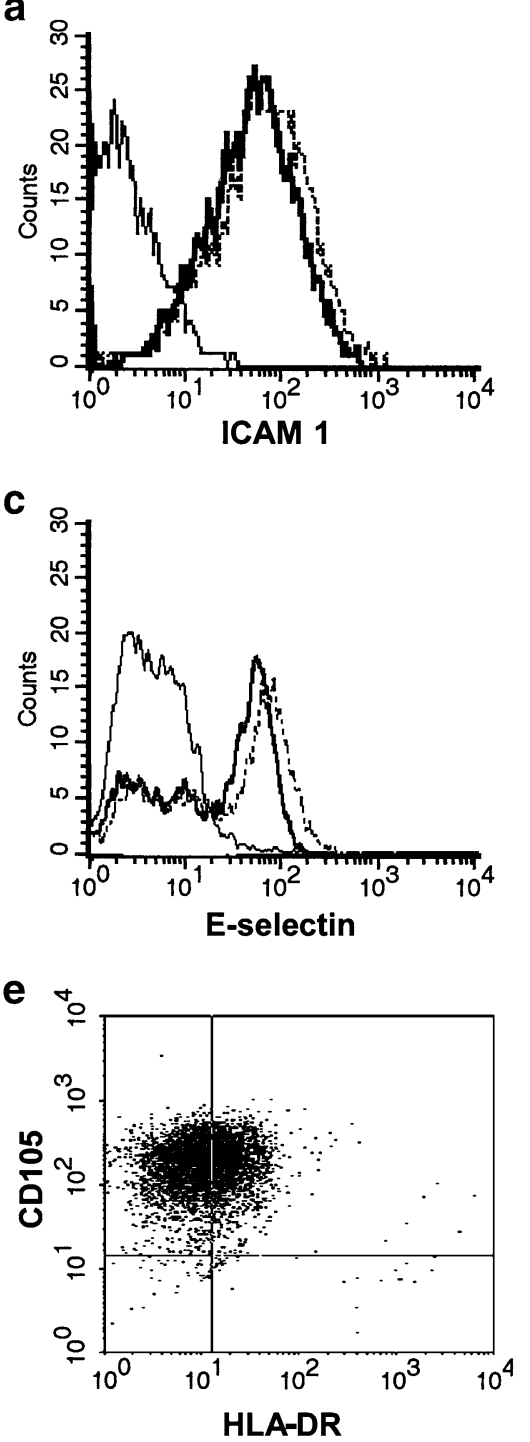

b
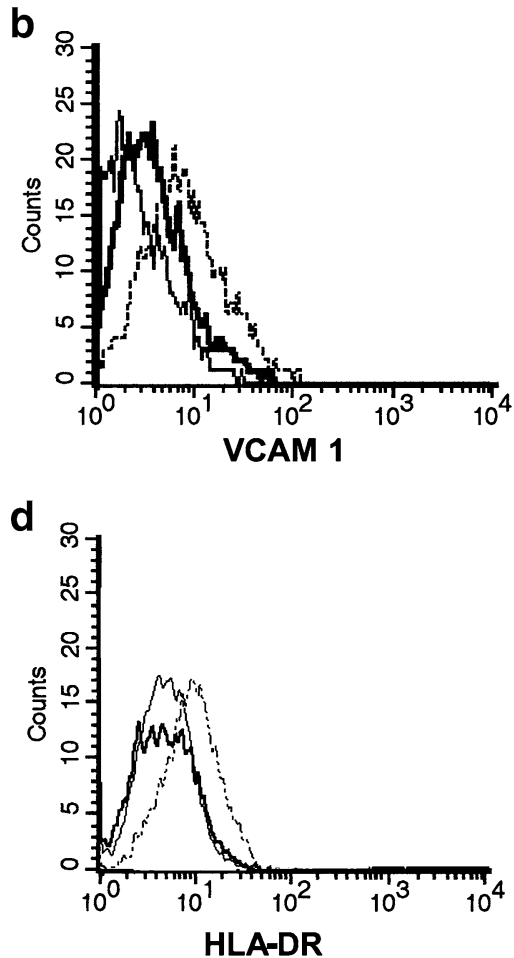

nucleoli were no longer visible due to the thickening of the cell bodies resulting from the retraction of peripheral cytoplasm. These characteristics were entirely retained by the immortalised cells.
Immortalised islet MECs had the ability to grow to a higher density than primary cells (confluent primary cultures contained mean $1.5 \times 10^{6}$ cells $/ 25-\mathrm{cm}^{2}$ flask, whereas immortalised cultures contained up to $2.8 \times 10^{6}$ cells $/ 25-\mathrm{cm}^{2}$ flask) and reached confluence within 5 to

Table 2 Mean fluorescence intensity and percentage of cells positive for expression of ICAM1, VCAM1 and E-selectin, both basally and after $4 \mathrm{~h}$ of TNF treatment

\begin{tabular}{|c|c|c|c|c|c|}
\hline & & \multicolumn{2}{|c|}{ Primary islet MECs } & \multicolumn{2}{|c|}{ Immortalised islet MECs } \\
\hline & & MFI & Percentage of positive cells & MFI & Percentage of positive cells \\
\hline \multirow[t]{2}{*}{ ICAM1 } & Basal & $57.3 \pm 33$ & $69.7 \pm 14.5$ & $55.8 \pm 28.5$ & $79.4 \pm 11.2$ \\
\hline & $+\mathrm{TNF}$ & $70.7 \pm 16$ & $78 \pm 4$ & $62.2 \pm 21.4$ & $74 \pm 22.8$ \\
\hline \multirow[t]{2}{*}{ VCAM1 } & Basal & $9.7 \pm 9$ & $18.9 \pm 22$ & $12.9 \pm 6$ & $37.7 \pm 15.3$ \\
\hline & $+\mathrm{TNF}$ & $26.1 \pm 5.5$ & $51.6 \pm 2$ & $21 \pm 7$ & $46 \pm 15$ \\
\hline \multirow[t]{2}{*}{ E-selectin } & Basal & $16 \pm 4$ & $25 \pm 7$ & $18 \pm 2$ & $31 \pm 5$ \\
\hline & $+\mathrm{TNF}$ & $30 \pm 6$ & $32 \pm 12$ & $30 \pm 2$ & $33 \pm 7$ \\
\hline
\end{tabular}

Data are expressed as mean value $\pm \mathrm{SD}$ of four to six separate experiments for each flow cytometric analysis. There was no statistical difference between primary and immortalised cells for all adhesion molecules. MFI mean fluorescence intensity, ICAMI intercellular adhesion molecule-1, VCAM1 vascular adhesion molecule-1 
6 days, whereas primary cultures, after the earlier passages, reached confluence in 9 to 10 days.

The BrdU proliferation assay showed greater DNA synthesis in the immortalised MECs than in primary cells, especially in the late passages (Fig. 2).

Primary islet MECs had a limited life span. Although remaining viable in culture without detaching from the monolayer, they underwent progressive growth arrest and proliferation decreased after approximately seven to eight passages. In contrast, SV40-treated cells had a longer life span than cells from primary cultures. Indeed, to date these cells have been cultured for approximately 30 passages over a span of 150 days.

Immunoperoxidase staining showed that over $90 \%$ of the cells of the immortalised islet MEC line were positive for the presence of SV40 large T-Ag within their nuclei. The expression of functional large $\mathrm{T}$ protein was confirmed by PCR analysis detecting the complete specific transcript in immortalised MECs as a band of 212 bp (Fig. 3a). We found an increase in the intensity of the nuclear staining among early and late passages of the immortalised cultures (Fig. 3b,c); these differences were confirmed by seminested PCR analysis of large T-Ag DNA (Fig. 3d), indicating that during serial subcultures there may be a progressive selection of cells expressing high levels of large T-Ag.

Immortalised islet MECs were not able to form colonies in soft agar, but their growth was serum- and anchoragedependent and contact-inhibited, thus suggesting a lack of tumorigenic transformation [32]. When implanted subcutaneously in SCID mice, these cells had not induced tumours at 1-month follow up.
Primary and immortalised islet MECs maintained endothelial cell characteristics, as assessed by detection of vWF expression and endothelial-cell associated markers, i.e. endoglin (CD105), CD31, VE-cadherin, and transmembrane glycoprotein melanoma cell adhesion molecule (CD146), by fluorescence assisted cell sorting analysis (Fig. 4a-e). Expression of these molecules was retained when reassessed after every three or four subcultures (Table 1). Moreover, early passages of both cells have been cryopreserved in liquid nitrogen and subsequently thawed, with no major changes in phenotype.

Notably, the specific expression of nephrin and Api persisted in the immortalised counterparts (Fig. 4f,g).

Both primary and immortalised islet MECs formed capillary-like structures when cultured on Matrigel. Both cell types demonstrated cord formation as early as after $2 \mathrm{~h}$ and well developed networks of capillary-like structures were present by $24 \mathrm{~h}$ (Fig. $4 \mathrm{~h}$ ).

\section{Expression of adhesion molecules}

After cytofluorimetric analysis primary and immortalised islet MECs showed high basal expression of ICAM1 (CD54), low basal expression of E-selectin (CD62E) and no detectable expression of VCAM1 (CD106) (Fig. 5a-c). TNF treatment upregulated ICAM1 and E-selectin, and induced neo-expression of VCAM1. Table 2 summarises MFI and the percentage of cells positive for expression of ICAM1 and VCAM1 and E-selectin, both basally and after TNF treatment. There were no statistical differences between primary and immortalised cells for expression of
Fig. 6 Adhesion of PBMCs on immortalised MEC monolayer. Flow cytometric analysis of harvested adherent PBMCs on untreated (a) and TNF-treated $(10 \mathrm{ng} / \mathrm{ml}$ for $12 \mathrm{~h})(\mathbf{b}) \mathrm{MEC}$ monolayers. In the two-parameter cytograms, PBMCs $\left(\mathrm{CD} 45^{+}\right.$, $\mathrm{CD} 14^{-}$) are represented as signals in the lower right-hand quadrant, whereas monocytes $\left(\mathrm{CD} 45^{+}, \mathrm{CD} 14^{+}\right)$are represented as signals in the upper righthand quadrant. c, d Inverted microscopy detection, in the same experimental conditions, of adherent PKH2-labelled PBMCs on untreated and TNFtreated islet MEC monolayer, respectively. Adherent PBMCs appear as bright spots. Bars: $10 \mu \mathrm{m}$. Primary cell monolayers exhibited similar results a
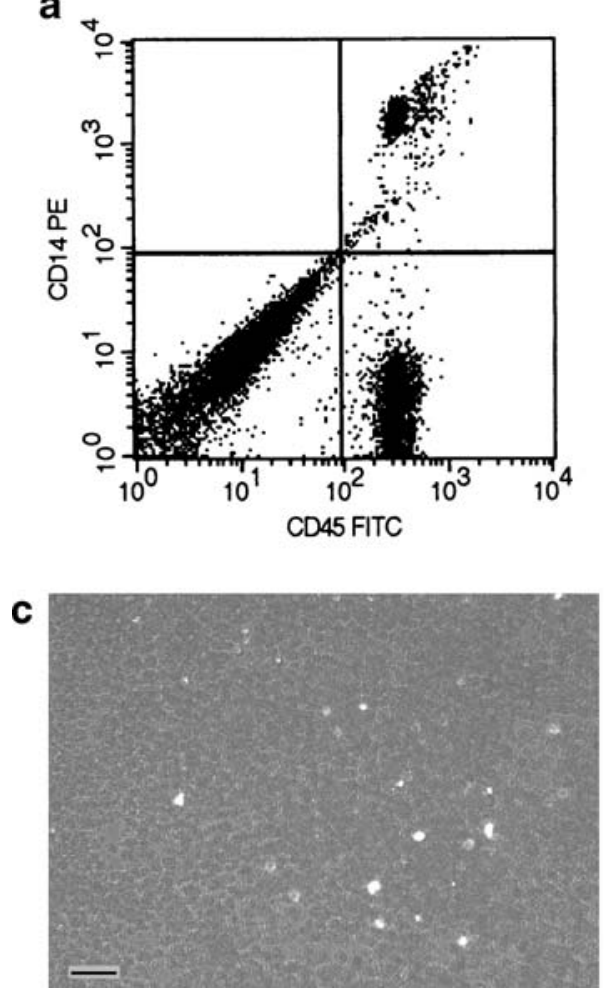

b
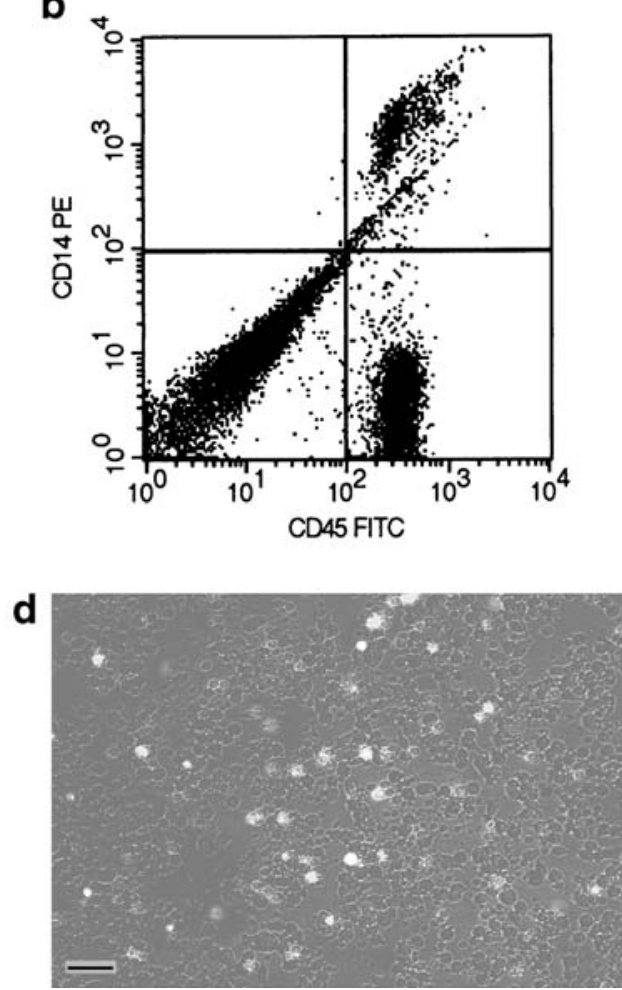
these surface molecules. Neither cell type expressed consistent, detectable CD40 or CD154 (CD40 ligand).

IFNG treatment induced expression of the HLA class II molecules HLA-DR. The magnitude of increase and the time-course of upregulation were similar in primary and immortalised cells (Fig. 5d,e).

\section{PBMC adhesion and migration}

We compared basal and TNF-induced adhesion of PBMCs with primary and immortalised islet MEC monolayers. Flow cytometric analysis of harvested adherent PBMCs and monocytes indicated that treatment with TNF increased adherence to primary cell monolayers (by approximately 40 and $30 \%$, respectively). TNF increased adherence of PBMCs and monocytes to immortalised cell monolayers in a similar way (Fig. 6a,b).

In parallel experiments, digital image analysis of $\mathrm{PKH} 2-$ labelled PBMCs showed that TNF enhanced PBMC adhesion to primary islet MEC monolayers (unstimulated control 19.4 \pm 7.4 PBMCs per microscope field, TNF stimulation 51.3 \pm 19 ) and immortalised monolayers (unstimulated control 19.5 \pm 6.7 , TNF stimulation $52.4 \pm 11$ ) (Fig. 6c,d). No statistical difference between primary and immortalised cells was observed.

In PBMC migration experiments, no cells were detectable in the lower chamber without TNF stimulation. Although TNF stimulation increased albumin diffusion, only very few cells were seen in the lower chamber at either 4 or $12 \mathrm{~h}$ after stimulation, with the amount of migrating cells reaching approximately $4 \%$ of seeded PBMCs at $18 \mathrm{~h}$ after stimulation. Results were similar using primary and immortalised MECs.

\section{Discussion}

The present work reports the establishment of the first SV40-immortalised cell line derived from isolated human pancreatic islet microvascular endothelial cells. This work was initiated in an attempt to overcome the drawbacks of working with primary islet endothelial cell cultures, e.g. difficulties in isolation, purification and propagation of large numbers of pure MECs, the same being true of other organs [33-36].

To date, there is only one study of purified human islet MECs [11], and it indicates that the isolation and propagation of MECs from pancreatic islets yields small numbers of cells, and that these cells exhibit a very low proliferation capacity, thus further hampering studies on pancreatic islet microendothelium. Moreover, these islet MECs show distinct morphological and functional characteristics. Notably, they have surface fenestrae [11-13], which are maintained by vascular endothelial cell growth factor and are possibly involved in rapid substance exchange and glucose sensing [12]. These cells express Api [11] and nephrin [19], and also induce insulin gene expression during islet development [14].
In our study, we purified islet MECs that are known to reside within isolated islets and that retain proliferative potential $[37,38]$. The purified islet MECs obtained and cultured by us do not exhibit the typical cobble-stone like endothelial phenotype and have surface fenestrations, as shown in vivo $[9,10]$; treatment with TNF alters their shape due to cytoskeletal reorganisation [31]. These cells express constitutively high baseline surface levels of the major adhesion molecule ICAM1, and they also express Eselectin and VCAM1 after TNF induction, with a pattern similar to that seen in other microendothelial cell lines, such as human microvascular endothelial cell line-1 [6,39].

We also characterised the immunological profile of these islet MECs, since it is well established that endothelial cells have a role in inflammatory processes, being able to secrete numerous cytokines and chemokines, and participate in presentation of antigens to $\mathrm{T}$ cells [25, 40-42]. Indeed, during insulitis in type 1 diabetes, endothelial cells surrounding the islets have been shown to assume an activated phenotype [20-24]. IFNG treatment of the islet MECs obtained by us induced expression of HLA class II molecules, whose function is to present antigen to $\mathrm{CD} 4^{+} \mathrm{T}$-cells.

Studies of endothelial-leucocyte interaction, in a static assay, showed enhanced adhesion of blood mononuclear cells induced by TNF, probably mediated by upregulation of the surface molecules involved in this process. Furthermore, the endothelial monolayer formed a barrier to lympho-monocyte transmigration, and although TNF increased permeability, it only minimally enhanced lymphomonocyte passage across the monolayer, indicating that other, additional mediators of inflammation and surface molecule interaction are needed [40].

However, as for all human diploid cells, the primary islet MECs in culture had a limited life span, with progressive reduction of their proliferation capacity until significant senescence and irreversible growth arrest set in [43]. This rendered it even more desirable to establish an immortalised cell line, with the additional aim of circumventing the variability associated with repeated primary isolation and the effects of propagation. However, the process of immortalisation may conceivably result in phenotypic changes, such as reduction in surface antigens and reduced responsiveness to cytokines [8, 44]. By SV40 transfection of early-passage primary cells, we generated an immortalised islet MEC line that has a longer life span than that of primary cells, with a continuous period of vigorous growth. It is known that SV40 large T-Ag can induce immortalisation of the cells by interfering with several pathways related to cell cycle control through the binding and blockade of tumour suppressor proteins such as $\mathrm{p} 53, \mathrm{pRb}$, $\mathrm{p} 107$, and $\mathrm{p} 130 / \mathrm{Rb} 2[43,45]$. In the present study, over $90 \%$ of the cells of the immortalised islet MEC line were positive for nuclear staining specific to SV40 large T-Ag, and molecular evidence indicated that the complete gene sequence was present in cultured cells. These findings unequivocally indicate that replicative senescence of islet MECs was bypassed by the stable expression of SV40 large T-Ag. Although phenotypically homogeneous and stable, the cell line established represents a non-clonal 
population of cells, which could eventually be subcloned by limiting dilution.

Cellular immortalisation is known to be a prerequisite of cell transformation [32]. It is known that different cell types are extremely heterogeneous in susceptibility to SV40mediated transformation [46], which requires the expression of the complete early region (large and small T-Ag) of the virus [47]. The islet MECs in our study expressed the SV40 large T-Ag, and although rapidly expanding, maintained the morphology of the primary cells. Their growth was contact-inhibited, serum-dependent and anchoragedependent, thus excluding a relevant dedifferentiation process; this could be due to the lack of expression of SV40 small T-Ag, which is considered necessary to generate tumorigenic human cells [47]. Preliminary in vivo experiments further suggest the absence of tumorigenic potential. We also demonstrate that these cells retain important biological features characteristic of the parental cells. Our immortalised cells, in fact, behave similarly to primary cells in functional terms, comparing favourably with primary cultures in adhesion molecule expression, support of leucocyte adhesion, and barrier function. Notably, our immortalised cells can still be activated, as shown by TNF stimulation and consequent adhesion molecule upregulation and enhanced adhesion of mononuclear cells, and by INFG induction of HLA class II molecules. They also persistently maintained the endothelial phenotype, thereby serving as a continuously renewable cell line. Notably, they retained expression of Api, an enzyme inhibitor and immune regulator [48, 49], and of nephrin, a transmembrane protein with structural, adhesion and signalling functions, both of which appear to be specific to islet MECs [11, 19].

In conclusion, the immortalised microendothelium described here represents a pancreatic islet endothelial cell line capable of growth and stable phenotype. There is no reason why these cells should not represent their primary counterparts in functional assays, becoming useful tools in dissecting the role of islet microendothelium in the pathophysiology of diabetes mellitus, as well as in developing intervention strategies to achieve optimal engraftment and function of transplanted islets, which is highly dependent on revascularisation [50].

Acknowledgements This work was supported by a grant from Regione Piemonte, Italy, Ricerca Sanitaria Finalizzata 2003, and by MURST (Ministry for Universities and Research), Italy, Progetto FIRB (n.RBAU013W3J-004). E. Favaro is supported by Regione Piemonte. M. Peakman is a Diabetes UK Senior Clinical Research Fellow. B. Lozanoska-Ochser is supported by Diabetes UK. A. Bottelli and E. Ferioli are supported by grants from the University of Insubria, Italy. P. G. Conaldi is supported by PRIN-MIUR, Italy 2003. We thank Dr M. C. Deregibus (Dept of Internal Medicine, University of Turin, Italy) for the SEM studies, and Dr S. Buttiglieri (CeRMS, University of Turin) for cloning the full-length SV40 large T-Ag coding gene and providing us with the designed primers for RTPCR. We are grateful to Dr James Greening for collaboration in the generation of human islet endothelial cells.

\section{References}

1. Michiels C (2003) Endothelial cell function. J Cell Physiol 196:430-443

2. Carlos TM, Harlan JM (1994) Leukocyte-endothelial adhesion molecules. Blood 84:2068-2101

3. Kubota Y, Kleinman H, Martin GR, Lawley TJ (1988) Role of laminin and basement in the differentiation of human endothelial cells into capillary-like structures. J Cell Biol 107:15891598

4. Charo IF, Shak S, Karasek MA, Davison P, Goldstein IM (1984) Prostaglandin $\mathrm{I}_{2}$ is not a major metabolite of arachidonic acid in cultured endothelial cells from human foreskin microvessels. J Clin Invest 7:914-919

5. Swerlick RA, Lee KH, Wick TM, Lawley TJ (1992) Human dermal microvascular endothelial cells but not human umbilical vein endothelial cells express CD36 in vivo and in vitro. J Immunol 148:78-83

6. Swerlick RA, Garcia-Gonzalez E, Kubota Y, Xu Y, Lawley TJ (1991) Studies of the modulation of MHC antigen and cell adhesion molecule expression on human dermal microvascular endothelial cells. J Invest Dermatol 97:190-196

7. Fujimoto T, Singer SJ (1988) Immunochemical studies of endothelial cells in vivo: II. Chicken aortic and capillary endothelial cells exhibit different cell-surface distributions of the integrin complex. J Histochem Cytochem 36:1309-1317

8. Lidington EA, Moyes DL, McCormack AM, Rose ML (1999) A comparison of primary endothelial cells and endothelial cell lines for studies of immune interactions. Transpl Immunol 7:239-246

9. Vajkoczy P, Olofsson AM, Lehr HA et al (1995) Histogenesis and ultrastructure of pancreatic islet graft microvasculature. Evidence for graft revascularization by endothelial cells of host origin. Am J Pathol 146:1397-1405

10. Lukinius A, Jansson L, Korsgren O (1995) Ultrastructural evidence for blood microvessels devoid of an endothelial cell lining in transplanted pancreatic islets. Am J Pathol 146:429435

11. Lou J, Triponez F, Oberholzer J et al (1999) Expression of alpha-1 proteinase inhibitor in human islet microvascular endothelial cells. Diabetes 48:1773-1778

12. Lammert E, Gu G, McLaughlin M et al (2003) Role of VEGF$\mathrm{A}$ in vascularization of pancreatic islets. Curr Biol 13:1070 1074

13. Esser S, Wolburg K, Wolburg H, Breier G, Kurzchalia T, Risau W (1998) Vascular endothelial growth factor induces endothelial fenestrations in vitro. J Cell Biol 140:947-959

14. Lammert E, Cleaver O, Melton D (2001) Induction of pancreatic differentiation by signals from blood vessels. Science 294:564-567

15. Sakamoto C, Goldfine ID, Roach E, Williams JA (1985) Localization of saturable CCK binding sites in rat pancreatic islets by light and electron microscope autoradiography. Diabetes 34:390-394

16. Treutelaar MK, Skidmore JM, Dias-Leme CL et al (2003) Nestin-lineage cells contribute to the microvasculature but not endocrine cells of the islet. Diabetes 52:2503-2512

17. Bonner-Weir S (1994) Regulation of pancreatic beta-cell mass in vivo. Recent Prog Horm Res 49:91-104

18. Duvillie B, Currie C, Chrones T et al (2002) Increased islet cell proliferation, decreased apoptosis, and greater vascularization leading to beta-cell hyperplasia in mutant mice lacking insulin. Endocrinology 143:1530-1537

19. Zanone MM, Favaro E, Doublier S et al (2005) Expression of nephrin by human pancreatic islet endothelial cells. Diabetologia 48:1789-1797

20. Hanninen A, Taylor C, Streeter PR et al (1993) Vascular addressins are induced on islet vessels during insulitis in nonobese diabetic mice and are involved in lymphoid cell binding to islet endothelium. J Clin Invest 92:2509-2515 
21. Hanninen A, Jalkanen S, Salmi M, Toikkanen S, Nikolakaros G, Simell O (1992) Macrophages, T cell receptor usage, and endothelial cell activation in the pancreas at the onset of insulin-dependent diabetes mellitus. J Clin Invest 90:19011910

22. Alejandro R, Shienvold FL, Hajek SV, Ryan U, Miller J, Mintz DH (1982) Immunocytochemical localization of HLA-DR in human islets of Langerhans. Diabetes 31 (Suppl 4):17-22

23. Itoh N, Hanafusa T, Miyazaki A et al (1993) Mononuclear cell infiltration and its relation to the expression of major histocompatibility complex antigens and adhesion molecules in pancreas biopsy specimens from newly diagnosed insulindependent diabetes mellitus patients. J Clin Invest 92:23132322

24. Somoza N, Vargas F, Roura-Mir C et al (1994) Pancreas in recent-onset insulin-dependent diabetes mellitus: changes in HLA, adhesion molecules and autoantigens, restricted T-cell receptor $\mathrm{V}$ beta usage, and cytokine profile. J Immunol 153:1360-1377

25. Savinov AY, Wong FS, Stonebreker AC, Chervonsky AV (2003) Presentation of antigen by endothelial cells and chemoattraction are required for homing of insulin-specific $\mathrm{CD}^{+}$T cells. J Exp Med 197:643-656

26. Jaffe EA, Nachman RL, Becker CG, Minick CR (1973) Culture of human endothelial cells derived from umbilical veins. Identification by morphological and immunological criteria. J Clin Invest 52:2745-2756

27. Page C, Rose M, Yacoub MH, Pigott R (1992) Antigenic heterogeneity of vascular endothelium. Am J Pathol 141:673683

28. Huang GC, Zhao M, Jones P et al (2004) The development of new density gradient media for purifying human islets and isletquality assessments. Transplantation 77:143-145

29. Conaldi PG, Bottelli A, Baj A et al (2002) HIV-1 Tat induces hyperproliferation and dysregulation of renal glomerular epithelial cells. Am J Pathol 161:53-61

30. Martini F, Lazzarin L, Iaccheri L et al (2002) Different simian virus 40 genomic regions and sequences homologous with SV40 large T Antigen in DNA of human brain and bone tumors and of leukocytes from blood donors. Cancer 94:1037-1048

31. Camussi G, Turello E, Bussolino F, Baglioni C (1991) Tumor necrosis factor alters cytoskeletal organization and barrier function of endothelial cells. Int Arch Allergy Appl Immunol 96:84-91

32. Hahn WC (2002) Immortalization and transformation of human cells. Mol Cells 13:351-361

33. Dong QG, Bernasconi S, Lostaglio S et al (1997) A general strategy for isolation of endothelial cells from murine tissues: characterization of two endothelial cell lined from the murine lung and subcutaneous sponge implants. Arterioscler Thromb Vasc Biol 17:1599-1604

34. Gerritsen ME, Shen CP, McHugh MC et al (1995) Activationdependent isolation and culture of murine pulmonary microvascular endothelium. Microcirculation 2:151-163
35. Marelli-Berg FM, Peek E, Lidington EA, Stauss HJ, Lechler RI (2000) Isolation of endothelial cells from murine tissues. J Immunol Methods 244:205-215

36. Kanda S, Landgren E, Ljungstrom M, Claesson-Welsh L (1996) Fibroblast growth factor receptor-1-induced differentiation of endothelial cell line established from tsA58 large T transgenic mice. Cell Growth Differ 7:383-395

37. Linn T, Schneider K, Hammes HP et al (2003) Angiogenic capacity of endothelial cells in islets of Langherans. FASEB J 17:881-883

38. Zhang N, Richter A, Suriawinata J et al (2004) Elevated vascular endothelial growth factor production in islets improves islet graft vascularization. Diabetes 53:963-970

39. Ades WE, Candal FJ, Swerlick RA et al (1992) HMEC-1: establishment of an immortalized human microvascular endothelial cell line. J Invest Dermatol 99:683-690

40. Greening JE, Tree TI, Kotowicz K et al (2003) Processing and presentation of the islet autoantigen GAD by vascular endothelial cells promotes transmigration of autoreactive $\mathrm{T}$ cells. Diabetes 52:717-725

41. Marelli-Bergerg FM, Frasca L, Weng L, Lombardi G, Lechler RI (1999) Antigen recognition influences transendothelial migration of $\mathrm{CD}^{+} \mathrm{T}$ cells. J Immunol 162:696-703

42. Pober JS, Kluger MS, Schechner JS (2001) Human endothelial cell presentation of antigen and the homing of memory/effector T cells to skin. Ann NY Acad Sci 941:12-25

43. Jha KK, Banga S, Palejwala V, Ozer HL (1998) SV40-mediated immortalization. Exp Cell Res 245:1-7

44. Harder R, Uhlig H, Kashan A et al (1991) Dissection of murine lymphocyte-endothelial cell interaction mechanisms by SV-40transformed mouse endothelial cell lines: novel mechanisms mediating basal binding, and alpha 4-integrin dependent cytokine-induced adhesion. Exp Cell Res 197:259-267

45. Saenz-Robles MT, Sullivan CS, Pipas JM (2001) Transforming functions of Simian virus 40. Oncogene 20:7899-7907

46. Bocchetta M, Di Resta I, Powers A et al (2000) Human mesothelial cells are unusually susceptible to Simian virus 40mediated transformation and asbestos cocarcinogenicity. Proc Natl Acad Sci USA 97:10214-10219

47. Hahn WC, Dessain SK, Brooks MW et al (2002) Enumeration of the Simian virus 40 early region elements necessary for human cell transformation. Mol Cell Biol 22:2111-2123

48. Cepinskas G, Noseworthy R, Kvietys PR (1997) Transendothelial neutrophil migration. Role of neutrophil-derived proteases and relationship to transendothelial protein movement. Circ Res 81:618-626

49. Breit SN, Wakefield D, Robinson JP, Luckhurst E, Clark P, Penny R (1985) The role of alpha 1-antitrypsin deficiency in the pathogenesis of immune disorders. Clin Immunol Immunopathol 35:363-380

50. Jansson L, Carlsson PO (2002) Graft vascular function after transplantation of pancreatic islets. Diabetologia 45:749-763 